\title{
Research on Agricultural Products Logistics and Supply Chain System Based on Computer Big Data Model
}

\author{
Wei $\mathrm{Yao}^{1}, \mathrm{Na} \mathrm{Li}^{1}$ \\ ${ }^{1}$ School of Intelligent Manufacturing And Service Shandong Institute Of Commerce And Technology, Jinan 250103, China
}

\begin{abstract}
With the development of the market, the traditional production and circulation mode of agricultural products can no longer meet the requirements of market informatization and supply chain development. Therefore, it is necessary to study a new production and circulation method of agricultural products to solve the problems caused by traditional methods. We build an innovation system for agricultural product supply chains led by big data service providers, integrating agricultural product supply chain resources, reducing agricultural product circulation links, reducing costs, achieving agricultural product traceability, and ensuring agricultural product quality and safety. Based on this, this article proposes an agricultural product supply chain model based on an integrated management platform, and conducts in-depth research on the logistics operation logic of agricultural product supply chain to provide theoretical basis and data support for the design and development of the management platform.
\end{abstract}

\section{Introduction}

China is a big agricultural country, and the development of agricultural products determines the development of China's economy. Therefore, it is necessary to improve the cooperative logistics operation mechanism of the supply chain of agricultural products to make China's agricultural development to a higher level. The continuous reform of the agricultural product logistics industry is the primary concern of the "three rural" issues at this stage, which is related to the progress environment of the national economy. First of all, we must understand that the logistics industry is a composite service business that combines goods circulation, storage and information technology, and it occupies a key position in the rapid development of the Internet today [1]. Doing a good job in the logistics of the agricultural industry is conducive to transportation and circulation, and facilitates the daily transactions of farmers, which is of great value to the promotion of China's new rural construction.

Scholars have done less research on integrating big data service providers into the agricultural product supply chain. However, in reality, big data service companies should provide one-stop services such as planting, packaging and sales, and development of sales channels for all links of the agricultural product supply chain. This article will combine cloud computing, big data and modern logistics technology to build a "cloud logistics" platform for the agricultural product supply chain.

\section{Feasibility analysis of cloud logistics platform for agricultural product supply chain}

\subsection{Development of agricultural product supply chain}

\subsubsection{Development of China's agricultural product supply chain}

Information has a guiding role in the circulation of agricultural products, so the degree of information sharing is the key to the circulation of agricultural products. At present, the main problem facing the development of China's agricultural product supply chain is the problem of information asymmetry. The asymmetry of information in the agricultural product supply chain has caused farmers, agricultural product processors, logistics providers, consumers and other major supply chain entities to face the following dilemma: In the agricultural product supply chain, as farmers, because the information channels are not smooth, it is too much. Farmers fail to obtain effective information before, during, and after crops are planted, resulting in increased production but not increased income, and low-price sales that hurt farmers. Compared with agricultural product processing enterprises, due to the information asymmetry of agricultural product production and supply and consumer demand, coupled with too many middlemen in the sales channel, the final profit of agricultural product processing enterprises is very small. The purchase price is particularly 
high. Compared with agricultural product logistics enterprises, due to the particularity of the agricultural product circulation process, the single acquisition channel of agricultural product logistics information has caused large losses for many agricultural products in the circulation process and increased the logistics cost of agricultural products. Due to the asymmetry of information in the entire agricultural product supply chain, consumers cannot effectively communicate with growers, middle-stream processors, and downstream distributors in the agricultural product supply chain, which increases the difficulty for consumers to obtain customized services for high-quality agricultural products. The above problems have become the influencing factors restricting the development of China's agricultural production and circulation [2].

\subsubsection{Development of foreign agricultural product supply chains}

In the United States, $78.5 \%$ of the agricultural product supply chain is "producer-distribution center-various retailers-consumer". The key to connecting this shortest network chain is the developed network information technology in the United States. Asia is represented by South Korea and Japan, Europe is represented by Germany, France, and the Netherlands, and the Americas are represented by the United States and Canada. They are all at the world's high-level logistics level in terms of agricultural product supply. One thing they have in common is that they all actively apply efficient information platforms to build efficient platforms for communication and transactions for various stakeholders without exception.

\subsection{The integration trend of agricultural product supply chain and cloud computing}

In 2015, in the "Guiding Opinions on Actively Promoting the "Internet +" Action" issued by the State Council, the development goals for the next ten years were clearly pointed out, which focused on "Internet + modern agriculture", "Internet + efficient logistics", and "Internet + efficient logistics". "Internet + e-commerce" and other action items. Use the Internet to create a new model of agricultural products circulation, improve the level of agricultural products in planting, processing, and management, form a logistics, quality and safety traceability system for agricultural products, and promote the development of agricultural modernization in China. Therefore, a new model of "Internet + agricultural product supply chain" was born. At present, cloud computing, big data and other technologies have become the basic support of "Internet +", and cloud computing as a new model of Internet services applied to the development of agricultural product supply chains has become a way and trend. In view of this, this article proposes the innovative model of agricultural product supply chain alliance of "suppliers + farmers + enterprises + sellers + big data service providers" as shown in Figure 1, and applies new technologies represented by big data, e-commerce, and the
Internet. In the agricultural product supply chain innovation alliance, in order to realize the synchronization and real-time sharing of upstream and downstream information of the agricultural product supply chain, construct the supply chain online and offline logistics, business flow, capital flow, and information flow to improve the circulation efficiency of agricultural products from farmland to consumers.

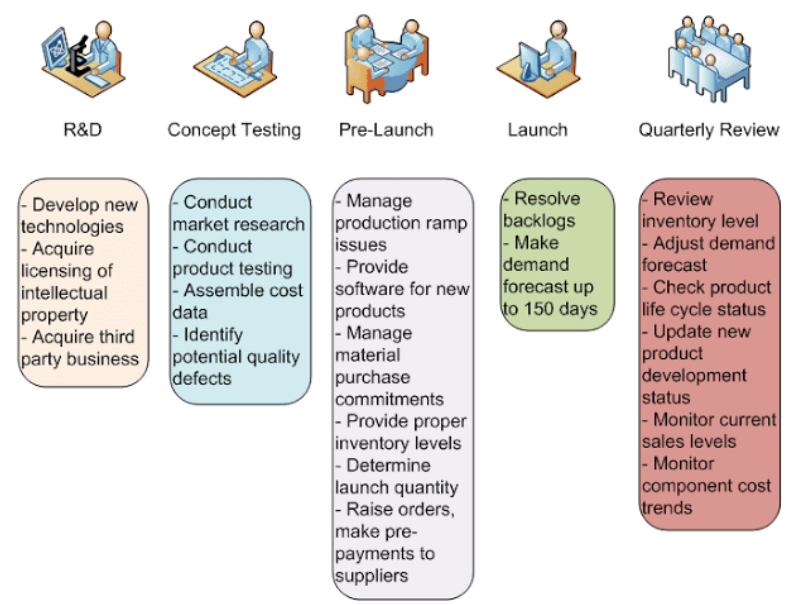

Figure.1. A map of the innovation alliance of agricultural product supply chain based on big data

\section{Construction of profit distribution model for agricultural product supply chain alliance}

\subsection{Raiffa algorithm model construction}

Regarding the research on the distribution of benefits, many scholars use the Shapley value method. However, the Shapley value method needs to know the benefits of each type of cooperation when solving. When there are $n$ cooperative enterprises, it is necessary to know the benefits of $2 n-1$ types of cooperation. When $n=4,5,6,7$, we need to know the benefits of $15,31,63,127$, cooperative alliances, which is obviously not in line with reality. Howard Raiffa also proposed a Raiffa solution to solve the problem of profit distribution of multi-party cooperative alliances based on the contribution of the partners. The only need to know the benefits of the alliance is $n+1$. Therefore, this article uses Raiffa's solution to distribute benefits to the members of the Big Data Agricultural Supply Chain Alliance. The basic algorithm is as follows: Suppose the set of members formed in the supply chain alliance is $\mathrm{N}=\{1,2, \quad, \mathrm{n}\}$, where any subset of $\mathrm{N}$ is denoted as $\mathrm{S}$ (that is, any combination of $\mathrm{n}$ alliance sets), let $\mathrm{V}(\mathrm{N})$ is the total income generated by the alliance, and $\mathrm{V}(\mathrm{S})$ is the total income of the sub alliance $\mathrm{S}$. The income function satisfies:

$$
V(\varnothing)=0 \quad \text { and } \quad V\left(\sum_{i=1}^{n} S_{i}\right) \geq \sum_{i=1}^{n} V\left(S_{i}\right)
$$

Suppose $\mathrm{V}(\mathrm{N})=\mathrm{B} ; V(S / i)=b i$, that is, the income when no member i participates in the cooperation of $n-1$ alliance members. 


\subsection{Algorithm improvement considering input factors and risk factors}

The Raiffa solution algorithm is similar to the Shapely value method. The core idea is to emphasize the contribution of the alliance members to the value of the supply chain, and distribute the benefits according to the marginal contribution of the alliance members to the supply chain alliance. Therefore, Raiffa's solution is a benefit distribution algorithm that only takes into account the influence of contribution factors. Research shows that the input of supply chain companies increases with the increase in the proportion of benefit distribution. And because in actual situations, there are high risks and high returns. Therefore, combined with the principle of fairness, it is necessary to comprehensively consider the input factors and risk factors to improve the Raiffa solution algorithm model.

In the supply chain alliance, due to the different tasks undertaken by each node enterprise, the ways to participate in the investment are also different. They are mainly divided into raw material investment $\mathrm{C} 1$, capital investment $\mathrm{C} 2$, infrastructure investment $\mathrm{C} 3$, technical investment $\mathrm{C} 4$, brand, Goodwill investment $\mathrm{C} 5$ and human resources investment C6 are six aspects. Quantify the input of raw materials into monetary value according to market prices; calculate the depreciation of enterprises during the operation of the supply chain to calculate the investment in infrastructure; quantify the input on the technical level through the value of market technology patents; use historical data or expert evaluation Method to calculate. Therefore, the input Ii of each cooperative member $i$ of the supply chain alliance can be expressed as:

$$
I_{1}+C_{1}+C_{2}+\ldots C_{6}, i=1,2,3, \ldots, n
$$

The value of risk is related to two parameters: one is the probability q that the risk occurs, and the other is the member's investment in the project I. Therefore, the risk value of member $i$ in the project can be described as:

$$
L_{i}=\left(q_{i}+\Delta q_{i}\right) I_{i}
$$

the risk, and Ii is the total investment of member i. $\Delta q_{i}$ is the risk compensation factor, and $\Delta q_{i}=q_{i}-1 / N$ is the ideal risk assumed by each member of the alliance. When $\Delta q_{i} \leq 0$, it means that the member's risk is lower than the ideal risk, and the corresponding part should be deducted from the original income. When $\Delta q_{i} \geq 0$ is, it means that the risk taken by the member is higher than the ideal risk, and the corresponding part should be added from the original income.

Taking into account the different degrees of contribution factors, input factors and risk factors on the supply chain alliance, in order to make the algorithm improvement more fair and reasonable, set the weight vector of the three factors on the alliance as $\varphi=\left(\varphi_{1}, \varphi_{2}, \varphi_{3}\right)$ ad $\sum_{i=1}^{3} \varphi_{i}=1 \cdot \varphi_{i}$ The specific value is given by experts or jointly determined by alliance members. In summary, after revising the Raiffa solution algorithm, the profit distribution formula of alliance members is:

$$
\begin{gathered}
w(i)=\varphi_{1} w(i)+\varphi_{2} \frac{I_{i}}{\sum_{i=1}^{n} I_{i}} V(N)+\varphi_{3} \frac{I_{i}}{\sum_{i=1}^{n} I_{i}} V(N), \\
I=1,2, \ldots, N
\end{gathered}
$$

\section{Selection of agricultural product logistics supply chain model}

At present, the degree of marketization, industrialization, and intensification of agricultural products is relatively low. In particular, fresh agricultural products have gone through many links from the field to the table. The circulation process presents a situation of cross and diversification. The circulation channels are multidirectional and the participants are scattered and diverse, as shown in Figure 2.

Among them, qi is the probability of member $i$ taking

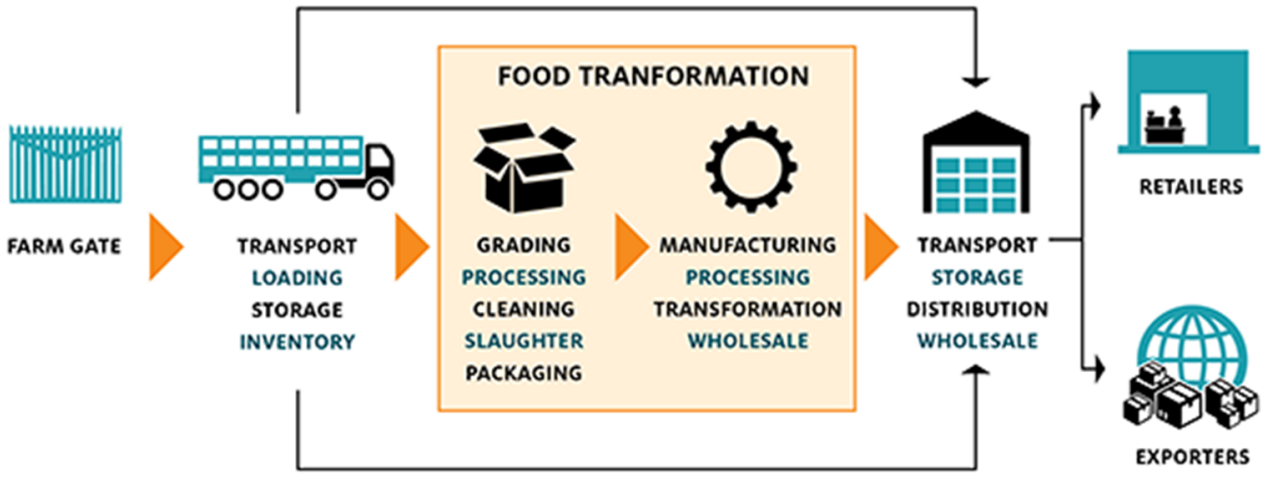

Figure.2. Traditional agricultural product supply chain model

\subsection{Agricultural product supply chain model centered on scattered farmers}

This model mainly uses scattered farmers as the main transaction body. Farmers usually directly trade with consumers at the roadside or nearby farmer's market in the field, and the transaction scale and quantity are small. For fresh and perishable agricultural products, they often lack professional preservation knowledge and technology, and are often at a disadvantage in the transaction process. 


\subsection{The agricultural product supply chain model centered on middlemen}

This model mainly involves middlemen purchasing agricultural products from farmers or farms, and then wholesale them to distributors, supermarkets and catering service providers for distribution. Due to the lack of information on market demand and market prices of farmers, the purchasers lower the purchase price of agricultural products, and farmers are at a disadvantage in the transaction. At the same time, purchasers through gradual distribution have led to a lengthy supply chain and increased links, increasing the difficulty of government supervision. From farmers, purchasers, wholesale markets, distributors and other links, each circulation link must increase prices, plus agricultural products. At the end of the consumer's table, the loss is several times higher than that of farmers' fields [3].

\subsection{Agricultural product supply chain model centered on leading enterprises}

This model is mainly based on the agricultural product supply chain model of leading enterprises and farmers. Farmers, under the organization and arrangement of the leading enterprise company, will uniformly plant the seeds and technical guidance issued by the company; the company will plant or breed agricultural products by farmers. Carry out unified production, processing, packaging and circulation, and provide agricultural products to consumers through retail stores and supermarkets. This kind of supply chain model is relatively stable compared with others, and can realize long-term transactions. The upstream and downstream flow of the agricultural product supply chain is smooth and the connection is relatively close. Under the supervision and guidance of the company, the quality of agricultural products is high, which is conducive to the improvement of the added value of agricultural products.

\subsection{Agricultural product supply chain model centered on farmer cooperatives}

This model is mainly for farmers to sell agricultural products in the name and method of cooperatives or associations through the establishment of professional cooperatives or farmers' associations. Due to the scattered farming households and the single and small number of agricultural products produced, cooperatives or farmers' associations facilitate the organization and mass sales of agricultural products, facilitate the large-scale transportation of agricultural products, and help farmers participate in market negotiations and have a certain right to speak in the market [4].

\section{Design of agricultural product supply chain platform under big data model}

\subsection{Operational elements of cloud logistics platform for agricultural product supply chain}

As shown in Figure 3, through the four agricultural product supply chain cloud logistics platform elements of supply, demand, cloud platform services, and logistics services, the interaction of information flow, logistics, business flow, and capital flow are realized.

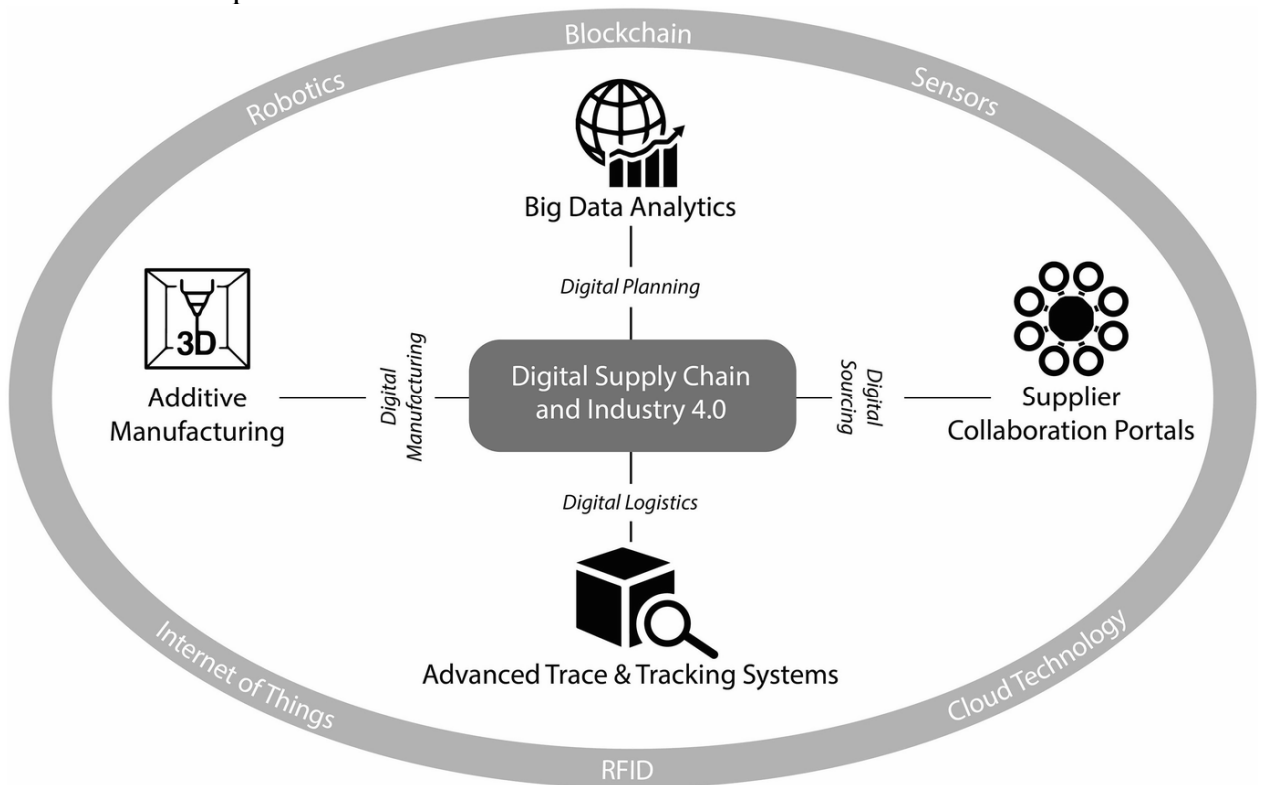

Figure.3.Operational elements of cloud logistics platform for agricultural product supply chain

\subsubsection{Supply}

Supply is the starting point of the agricultural product supply chain. Farmers, agricultural product processors, and suppliers (agricultural product distribution centers, etc.) can upload agricultural product supply information (quantity) through agricultural product supply chain cloud logistics platform application terminals such as personal computers, mobile phones, and other mobile terminals). 


\subsubsection{Requirements}

Demand is the end of the agricultural product supply chain, which mainly includes consumers, retail terminals, agricultural product distributors, etc., through the agricultural product supply chain cloud logistics platform application terminal to find supply information, and through the platform to inquire, negotiate, and trade. Demanders can also release demand information to the agricultural product supply chain cloud logistics platform, so that suppliers can produce according to orders.

\subsubsection{Cloud platform services}

Cloud platform service is the core of the cloud logistics platform of the agricultural product supply chain. It not only provides technical support for cloud services, but also provides cloud platform service support for the overall operation of the platform. Cloud platform services coordinate and deploy demand and supply through big data analysis and prediction, maintain supply balance, and improve the overall efficiency of the supply chain.

\subsubsection{Logistics Services}

The logistics services in the cloud logistics platform of the agricultural product supply chain include two parts: thirdparty logistics and platform logistics, which are uniformly allocated according to the requirements of supply and demand to improve logistics efficiency [5].

\subsection{Operation process of cloud logistics platform for agricultural product supply chain}

As shown in Figure 4, the agricultural product supply chain service platform first collects supply and demand information, and then the platform stores the collected information. Terminal demanders and suppliers can negotiate, negotiate, and trade on the platform through information interaction. At the same time, the platform will analyze and research the collected supply and demand information, feed it back to the platform users, and coordinate business flow, logistics, and capital flow based on the results of information processing.

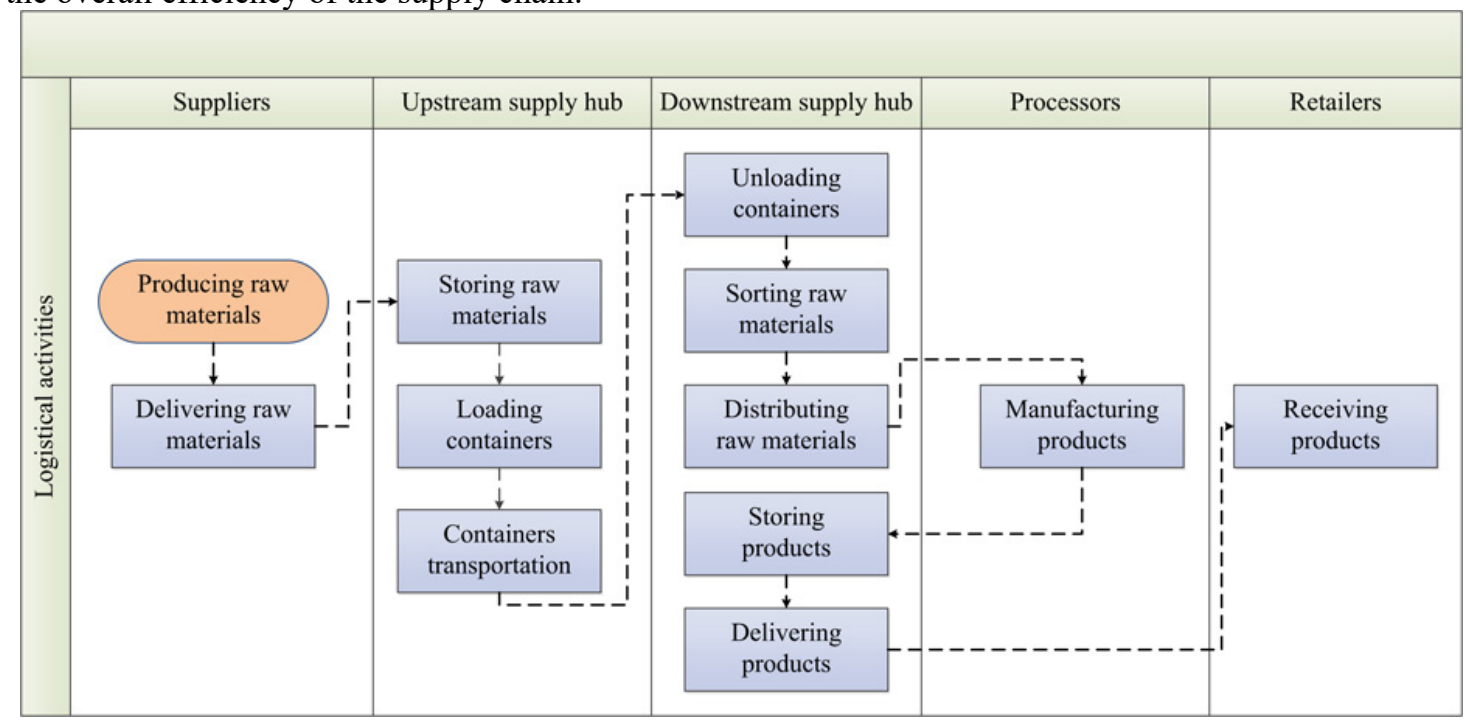

Figure.4.Operation flow chart of cloud logistics platform for agricultural product supply chain

\subsection{Analysis of Cloud Logistics Platform Architecture of Agricultural Products Supply Chain}

Based on the problems of poor information communication between the upstream and downstream of the agricultural product supply chain, information asymmetry in agricultural product production, processing, circulation, and distribution, and lack of supervision in each link, it is essential to establish a large data platform for agricultural product supply chain that is coordinated and governed by multiple parties, which can collect information on the production, processing, circulation, and distribution of agricultural products, release information on demand and supply of agricultural products in a timely manner, and analyze market and price information on agricultural products. At present, the Internet of Things technology and cloud computing technology can collect, store, analyze and integrate big data, which is conducive to realizing the timely sharing of information of producers, consumers, society, enterprises, and governments, and accelerating the reasonable integration and flow of information and data [6]. Figure 5 The agricultural product supply chain big data platform integrates relevant information resources such as the government, enterprises, society, and consumers, releases relevant agricultural product information in a timely manner, realizes the information sharing of agricultural products from the field to the table, promotes the coordination and value-added effects of agricultural products, and ensures The agricultural product supply chain is healthy, safe and sustainable. The agricultural product supply chain big data platform involves multiple departments, links and participants, including the government's agriculture, environmental protection, quality supervision, transportation, health, industry and commerce and other departments, involving agricultural product planting or breeding farmers, circulation companies, production and processing companies, and consumers Wait for multiple participants. 


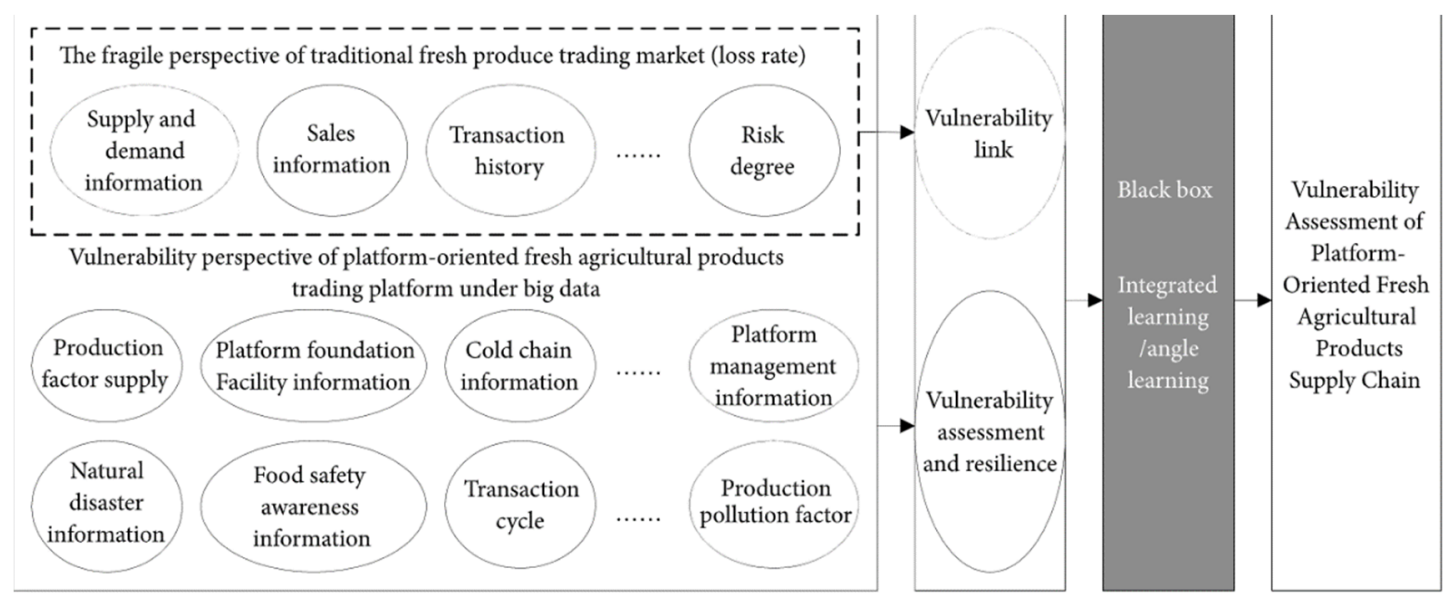

Figure.5.Big data platform of agricultural product supply chain

\subsection{Function analysis of big data platform of agricultural product supply chain}

Figure 5 shows the agricultural product supply chain big data platform adopts the idea of "Internet +" to realize the deep integration of the Internet and agricultural product supply, realize the organic integration of various circulation links, break the traditional fragmentation, and promote the deep integration of the participants in the agricultural product supply chain And actively participate in the realization of information sharing and coordinated development in all links of agricultural product supply, demand, processing, circulation, and distribution. The agricultural product supply chain big data platform mainly fulfills the following functions: (1) Through the establishment of a provincial or large regional agricultural product information platform, it is helpful to realize the cross-regional integration and circulation of agricultural product resources, realize the optimal allocation of resources, and facilitate the overall planning of all participants. Plan to realize the interconnection of agricultural product resources and the sharing of agricultural product information; (2) Break through the traditional single link supervision, a certain chain supervision, and realize the whole chain supervision from the field to the table; (3) From the traditional provision of data supply and demand The summarization, processing and analysis of data and information such as the supply quantity, demand quantity, processing enterprises, distribution network, etc. of agricultural products along the entire chain will transform from providing information to providing decision-making services; (4) Engaging in post-processing to pre-warning, risk prevention and control, extremely Greatly enhance the supervision efficiency and supervision of various government departments.

\subsection{Technical support of cloud logistics platform for agricultural product supply chain}

Basic cloud platform: It is the foundation of the cloud service platform, mainly for upper-level user-oriented terminals and basic cloud and application cloud services. At present, the main basic cloud platform services are based on Xen, and there are also cloud platforms based on
VM ware ESX technology. Basic cloud service: In this layer, it mainly plays the role of connecting the basic cloud platform and the display terminal. It is based on the basic cloud platform to provide services such as caching. These services can not only support the display terminal behind, but also can be directly accessed by users. Application cloud service and user display: This layer is mainly used to provide friendly application access to end users. JavaScript, CSS, and Flash are commonly used technologies.

\section{Ways to improve the informatization of agricultural product logistics supply chain}

\subsection{The government vigorously develops the big data intelligent supply chain}

Including the big data supply chain in the supply chain reform measures to improve the national economic development strategy level. At the same time, a special big data supply chain development committee was established to propose tasks such as the supply chain development framework, speed, and regional layout consistent with national economic development; and a clear big data intelligent supply chain development strategy, focusing on the development of agricultural big data supply The chain system aims to cultivate a big data intelligent supply chain system for advantageous industries and emerging industries.

\subsection{Enterprises promote the construction of big data intelligent supply chain}

Strengthen the training of technical talents such as enterprise big data and supply chain, strengthen mutual cooperation with professional enterprises such as big data service enterprises, logistics enterprises or supplier enterprises, and obtain technology and talents suitable for enterprise development. Technology is not the specialty of all companies. To use big data technology for data analysis, companies need to establish corresponding outsourcing policies. It is clear which tasks in the supply chain can be completed independently by the enterprise and which technical work needs to be cooperated with other partners 
[7].

\subsection{Promote the construction of agricultural big data intelligent supply chain}

Establish a new talent system in rural areas and cultivate talents in line with the development of modern agriculture to solve the problem of talent gaps in China's agricultural product supply chain alliance. The addition of academic and research parties to the agricultural product supply chain not only provides technical and management model guidance and talent transfer to the agricultural product supply chain alliance, but also solves the technical research and development problems in the agricultural product supply chain; using big data and Internet technology to innovate agricultural finance, Solve the problem of financing difficulties in traditional agricultural funds, so that the agricultural product supply chain has sufficient financial support. At the same time, allowing rural areas to obtain financing will help attract young people who have left the country to enter the city to return to the countryside.

\section{Conclusion}

The continuous improvement of the circulation of agricultural products is the primary concern of the "three rural" issues at this stage, and it is related to the environment for the progress of the national economy. This paper focuses on the agricultural product logistics supply chain operation system, starting from the supply chain coordination and agricultural and sideline product supply chain related theories, and analyzes the basic elements and basic characteristics of the existing agricultural product supply chain structure, and has a good Research on the mechanism and profit issues, hoping to have a positive impact on the establishment of the future agricultural product circulation operation mechanism.

\section{References}

1. Aloysius, J. A., Hoehle, H., Goodarzi, S., \& Venkatesh, V. Big data initiatives in retail environments: linking service process perceptions to shopping outcomes. Annals of Operations Research, vol. 270, pp. 25-51, January 2018.

2. Bailey, D. The emergence of supply chains and their potential impact on utah's food and agricultural products. Transfusion, vol. 50, pp. 1838-1848, August 2010.

3. Manggala, U. Analisis dan perancangan sistem esupply chain management pada pt. electronic solution indonesia. Hypertension, vol. 37, pp. 1341-8, May 2009.

4. Burns, T., Predale, R., Silva, P., \& Manley, J. B. Greening the supply chain to develop more sustainable formulations. Journal of Cosmetic Science, vol. 63, pp.273, April 2012.

5. Nunes, B., Bennett, D., \& Junior, S. M. Sustainable agricultural production: an investigation in brazilian semi-arid livestock farms. Journal of Cleaner Production, vol. 64, pp. 414-425, February 2014.

6. Bhattacharya, K. K., \& Singh, H. Agricultural resource planning through-it platform -an approach. Operational Research, vol. 5, pp. 49-65, January 2005.

7. Wade A. Givens, David R. Shaw, Greg R. Kruger, William G. Johnson, Stephen C. Weller, Bryan G. Young, Robert G. Wilson, Micheal D.K. Owen, \& Jordan, D. Survey of tillage trends following the adoption of glyphosate-resistant crops. Weed Technology, vol. 23, pp.150-155, January 2009. 